ALVES, D.P., SANTILIANO, F.C. e ALMEIDA, B.R. Epidemiologia das helmintoses gastrointestinais em bovinos. PUBVET, Londrina, V. 6, N. 25, Ed. 212, Art. 1414, 2012.

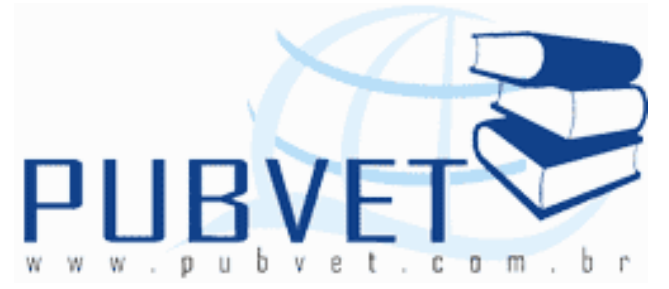

PUBVET, Publicações em Medicina Veterinária e Zootecnia.

\title{
Epidemiologia das helmintoses gastrointestinais em bovinos
}

Danielle Porcari Alves ${ }^{1}$, Fabiano Costa Santiliano², Bethânia Ribeiro de Almeida ${ }^{3}$

1 Médica Veterinária. Centro de Controle de Zoonoses de Cachoeiro de Itapemirim.

${ }^{2}$ Biólogo. Centro de Ciências Agrárias da Universidade Federal do Espírito Santo.

${ }^{3}$ Docente. Centro de Ciências Agrárias da Universidade Federal do Espírito Santo.

\section{Resumo}

Os helmintos gastrointestinais constituem-se em agentes etiológicos de significativa importância para a diminuição da produtividade na pecuária bovina. Entre os fatores que interferem no desenvolvimento da bovinocultura, as helmintoses gastrintestinais e pulmonares ocupam grande destaque por ocasionar perdas econômicas relacionadas à baixa produtividade do rebanho, retardamento do desenvolvimento dos animais, aumento na taxa de mortalidade de bovinos jovens e gastos excessivos com manejo e medicamentos. O parasitismo gastrintestinal em bovinos está freqüentemente associado à alta densidade populacional animal e a sistemas intensivos de manejo, principalmente relacionado à bovinocultura leiteira. Entretanto, nos ruminantes, o estado nutricional e particularmente a disponibilidade de proteínas e minerais é um fator importante na otimização da produtividade animal, interferindo na patogenia e 
ALVES, D.P., SANTILIANO, F.C. e ALMEIDA, B.R. Epidemiologia das helmintoses gastrointestinais em bovinos. PUBVET, Londrina, V. 6, N. 25, Ed. 212, Art. 1414, 2012.

nos mecanismos de resposta imune dos hospedeiros às infecções por nematódeos gastrointestinais. O efeito deste parasitismo na produção animal pode ser reduzido mediante alterações no manejo das pastagens e dos animais com a aplicação de anti-helmínticos. Para que tais procedimentos possam ser realizados, é necessário conhecer a biologia dos parasitos da região a ser estudada. Uma etapa da fase do ciclo destes parasitas ocorre no meio ambiente e vários fatores estão diretamente envolvidos no desenvolvimento e na sobrevivência das larvas nas pastagens e na manutenção das infecções nos animais, como: fatores climáticos, genéticos e características das pastagens. Objetivou-se com esta revisão realizar um levantamento epidemiológico das principais espécies de helmintos gastrintestinais que acometem bovinos em clima tropical, avaliando a prevalência das helmintoses na população de animais de acordo com a faixa etária e a interação destes parasitas nas perdas econômicas geradas na pecuária bovina.

Palavras-Chave: epidemiologia, helmintoses, perdas econômicas, bovinos.

\section{Epidemiology of bovine gastrointestinal helminthiasis}

\section{Abstract}

The gastrointestinal helminths are etiologic agents which have a great important in the decreasing of bovine's livestock productivity. Among the factors that affect the development of the cattle raising, the gastrointestinal and pulmonary helminthosis are really important as long as they cause economical waste related to the low rates of herd's productivity, delay on animal's growing, increased mortality rates of young cattle and excessive spending with management and medicaments. The gastrointestinal parasitism of bovines are often associated to the high numbers of animals in the farm and also to the intensive systems of handling, principally at the dairy cattle. However, talking about ruminants, the 
ALVES, D.P., SANTILIANO, F.C. e ALMEIDA, B.R. Epidemiologia das helmintoses gastrointestinais em bovinos. PUBVET, Londrina, V. 6, N. 25, Ed. 212, Art. 1414, 2012.

nutritional standards and particularly availability of minerals and proteins is an important factor in the optimization of animal's productivity, interposing in the pathogeny and in the immune response of harborers to the gastrointestinal infections caused by nematodes. The effects of this parasitism in animal production can be reduced by changes in pasture control and application of antihelmintics. For the success of this procedure, it is necessary to know the biology of the parasites of the region that is going to be studied. One stage of this parasite's cycle occurs in the environment and many factors are involved in the development and survival of larvas in the pasture and in the maintenance of infection at the animals, such as: climatic and genetical factors and pasturage peculiarities. This revision aims to make an epidemiologic weighing of the main species of gastrointestinal helminths that attack bovines in tropical climate, availing helminthosis prevalence in animal population according to the age-group and to the interaction of this parasites with the economical wastes in bovine pecuary.

Keywords: epidemiology, helminthosis, economical waste, bovines

\section{INTRODUÇÃO}

Segundo dados do IBGE (2005), o rebanho bovino brasileiro atingiu 207,2 milhões de animais, o que representou um aumento de 1,3\% em relação a 2004. O país tem o maior rebanho bovino comercial do mundo, os indicadores econômicos da pecuária estão subindo ano após ano e retornaram os investimentos na produção animal. No Estado do Espírito Santo, o rebanho está estimado em 1.925 .596 cabeças, o que demonstra o aumento da atividade pecuária neste estado.

A criação de ruminantes é uma atividade de relevante importância socioeconômica para o Brasil. Os bovinos, caprinos e ovinos representam uma das principais fontes protéicas para a população, sendo que a produção de carne, 
ALVES, D.P., SANTILIANO, F.C. e ALMEIDA, B.R. Epidemiologia das helmintoses gastrointestinais em bovinos. PUBVET, Londrina, V. 6, N. 25, Ed. 212, Art. 1414, 2012.

Iã, leite e derivados vêm crescendo a cada ano para atender a demanda do mercado consumidor. (ANUALPEC, 2003).

No Brasil grande parte da criação ainda é feita em regime de pasto ou parcial, o que leva a constantes infecções por parasitos presentes nas pastagens (PADILHA, 1996; ANUALPEC, 2003). Porém, animais sujeitos a uma criação mais intensiva são forçados a se alimentar sem muita seletividade e próximos aos bolos fecais. Isto faz com que adquiram cargas maiores de vermes, o que, somado ao fator nutricional, leva a uma queda de imunidade e maiores percentuais de mortalidade.

Os helmintos pulmonares e gastrintestinais constituem-se em agentes etiológicos de significativa importância para a diminuição da produtividade na pecuária bovina (PIMENTEL e FONSECA, 2002), principalmente devido ao impacto que causam na produção de carne e leite e aos altos custos das medidas de controle (HONER e BIANCHIN, 1987; WALLER e LARSEN, 1993).

Nas últimas décadas, algumas pesquisas têm sido realizadas para o desenvolvimento de novas moléculas de anti-helmínticos que causem poucos efeitos colaterais, pouca resistência dos parasitas, que sejam livres de resíduos químicos e que não causem danos ao meio ambiente (WALLER, 1997).

Importantes princípios da epidemiologia das helmintoses gastrintestinais de ruminantes foram fundamentados pela contribuição de diversos autores, sendo relatada principalmente a fauna helmíntica em animais jovens. TONGSON e BALEDIATA, 1972 verificaram que infecções helmínticas eram particularmente incidentes em animais com até 24 meses de idade, sendo a idade um fator determinante na prevalência de helmintos em bovinos.

Nishi, Richtzenhain e Gennardi (2002), após estudos mensurando os níveis de IgG sérica em bezerros experimentalmente infectados por Haemonchus placei, concluíram que bezerros submetidos a dieta protéica adequada apresentam maior produção de IgG sérico que os submetidos a dietas com níveis protéicos mais 
ALVES, D.P., SANTILIANO, F.C. e ALMEIDA, B.R. Epidemiologia das helmintoses gastrointestinais em bovinos. PUBVET, Londrina, V. 6, N. 25, Ed. 212, Art. 1414, 2012.

baixos. Além disso, observaram que bezerros infectados por $H$. placei desenvolvem um bom grau de resistência a reinfecções.

A literatura sobre o parasitismo por nematódeos gastrintestinais em bovinos em idade de abate é bastante escassa, pois a maioria das publicações disserta sobre o parasitismo em bovinos com idade inferior a um ano. BRESCIANI et al 2001, realizaram um estudo das helmintoses gastrintestinais em bovinos em idade de abate (entre 24 e 30 meses de idade) e encontraram os gêneros Cooperia, Haemonchus e Oesophagostomum. As espécies identificadas foram: Cooperia punctata, Cooperia pectinata, Haemonchus similis, Haemonchus placei e Oesophagostomum radiatum.

Objetivou-se com esta revisão realizar um levantamento epidemiológico das principais espécies de helmintos gastrintestinais que acometem bovinos em clima tropical, avaliando a prevalência das helmintoses na população de animais de acordo com a faixa etária e a interação destes parasitos nas perdas econômicas geradas na pecuária bovina.

\section{REVISÃO DE LITERATURA}

\subsection{Biologia e morfologia dos helmintos gastrintestinais de bovinos}

Helmintos são animais de simetria bilateral cujo corpo é revestido por cutícula e que podem apresentar a forma cilíndrica ou chata. Os helmintos compreendem dois filos: Nemathelminthes ou vermes cilíndricos, e Plathelminthes ou vermes chatos. O filo Plathelminthes é dividido nas classes Trematoda e Cestoda e o filo Nemathelminthes em Nematoda (CORRÊA, 1971).

Dentre os parasitos de maior importância em bovinos da classe Trematoda (Figura 1), a Fasciola hepatica destaca-se por causar queda na produção e na qualidade do leite, perda de peso dos animais, queda na fertilidade, atraso no crescimento, ocasionando em alguns casos a mortalidade (QUEIROZ et al., 2002). 
ALVES, D.P., SANTILIANO, F.C. e ALMEIDA, B.R. Epidemiologia das helmintoses gastrointestinais em bovinos. PUBVET, Londrina, V. 6, N. 25, Ed. 212, Art. 1414, 2012.

A $F$. hepatica (Figura 2) é considerada uma enfermidade de grande importância veterinária por causar danos diretos ao animal, elevadas perdas econômicas devido às lesões causadas no fígado e na carcaça, e por ser uma zoonose, afetando a saúde pública (SERRA - FREIRE, 1999).

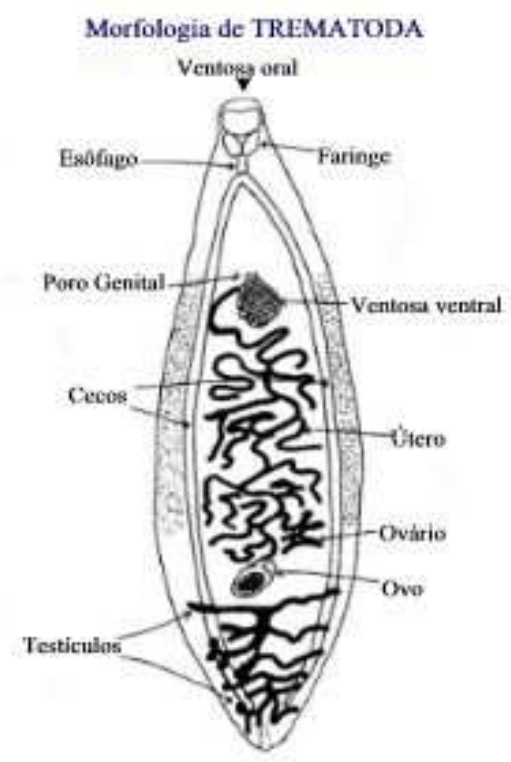

FIGURA 1: Representação esquemática da morfologia de um trematoda adulto. Fonte: Universidade Federal de Santa Maria. Disponível em: <http://w3.ufsm.br/parasitologia/arquivospagina/nematoda.htm> Acesso em: 10 maio 2012.

A Moniezia benedeni é uma taenia da classe Cestoda que acomete bovinos podendo causar grande variedade de sinais clínicos, incluindo definhamento, diarréia, sintomatologia respiratória e até mesmo convulsões, porém a infecção normalmente é assintomática. Na classe Nematoda (Figura 3) encontram-se a maior quantidade de parasitos gastrointestinais de bovinos, dentre eles destacam-se: Ostertagia ostertagi, Haemonchus contortus, H. placei, H. similis, Trichostrongylus axei, T. colubriformis, Cooperia oncophora, C. punctata, C. pectinata, Nematodirus battus, N. helvetianus, Oesophagostomum radiatum, 
ALVES, D.P., SANTILIANO, F.C. e ALMEIDA, B.R. Epidemiologia das helmintoses gastrointestinais em bovinos. PUBVET, Londrina, V. 6, N. 25, Ed. 212, Art. 1414, 2012.

Bunostomum phlebotomum, Strongyloides papillosus e Trichuris globulosa (URQUHART et al., 1996).

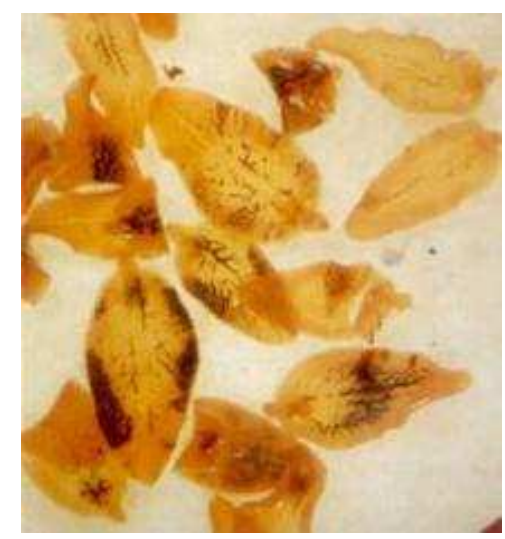

FIGURA 2: Formas adultas de Fasciola hepatica extraídas de fígado de bovino infectado. Fonte: Universidad de León. Disponível em: <http://www.veterinaria.org/asociaciones/vetuy/articulos/artic_bov/036/bov036. htm> Acesso em: 10 maio 2012.

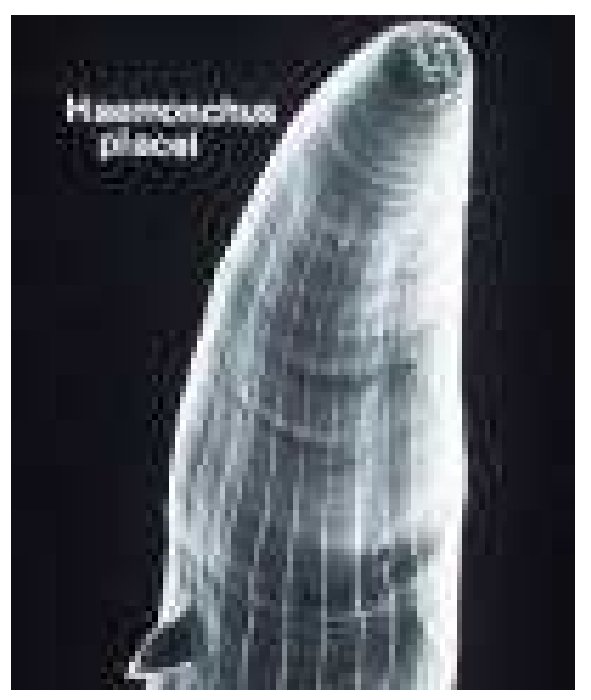

FIGURA 3: Representação esquemática de parasito aduto (Haemonchus placei) da classe Nematoda. Fonte: Universidad de Buenos Aires. Disponível em: <http://ar.geocities.com/vetterworld/parasitologia/helm_p_haemonchus.htm > Acesso em: 10 maio 2012. 
ALVES, D.P., SANTILIANO, F.C. e ALMEIDA, B.R. Epidemiologia das helmintoses gastrointestinais em bovinos. PUBVET, Londrina, V. 6, N. 25, Ed. 212, Art. 1414, 2012.

O ciclo biológico de grande parte dos nematóides gastrintestinais pode ser dividido em duas fases principais. A primeira fase é a infecção do hospedeiro (fase parasitária), quando o parasito adulto localiza-se em algum segmento do sistema gastroentérico e a segunda refere-se à fase de vida livre que se inicia com a liberação de ovos na pastagem através das fezes. Ocorre então a eclosão dos ovos, com subseqüente desenvolvimento das larvas de primeiro estádio (L1) em larvas de terceiro estádio ou infectantes (L3) em aproximadamente sete a quatorze dias (Figura 4) (GEORGI, 1982).

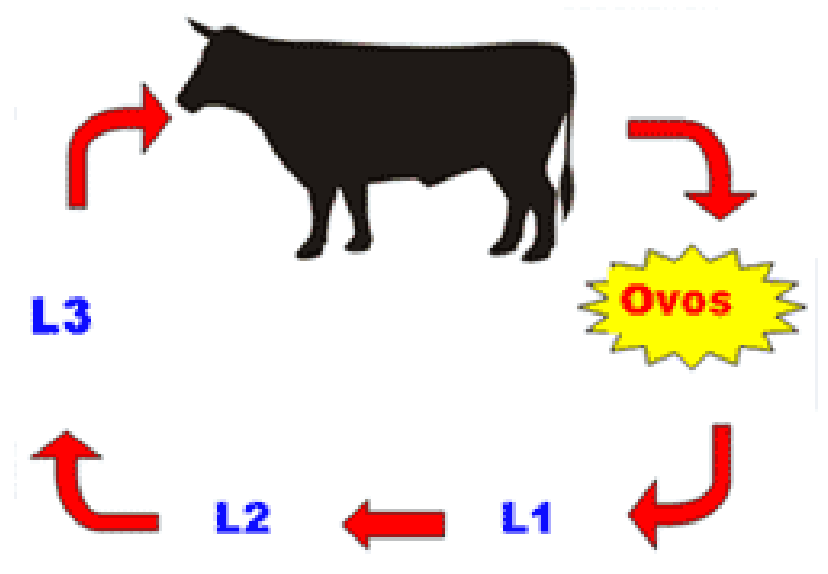

FIGURA 4: Ciclo biológico dos parasitos gastrintestinais de bovinos. Fonte: Disponível em: <http://www.higieneanimal.ufc.br/1shsao/images/henrique07.gif \&imgrefurl=http://www.higieneanimal.ufc.br/1shsao/palestras> Acesso em: 10 maio 2012.

A sobrevivência e o desenvolvimento das larvas requerem condições ambientais apropriadas que também influenciam a migração das larvas dos bolos fecais para as pastagens. Estas infectam seus hospedeiros principalmente por via oral. No Brasil, as larvas infectantes das principais espécies de parasitos estão disponíveis nas pastagens praticamente durante o ano todo, servindo de fonte de infecção contínua para os animais (LIMA, 1989). 
ALVES, D.P., SANTILIANO, F.C. e ALMEIDA, B.R. Epidemiologia das helmintoses gastrointestinais em bovinos. PUBVET, Londrina, V. 6, N. 25, Ed. 212, Art. 1414, 2012.

\subsubsection{Morfologia dos ovos}

Os ovos de helmintos encontrados em fezes de bovinos são quase os mesmos encontrados em ovinos e caprinos. De acordo com a espécie de parasito os ovos contém de 4 a 32 blastômeros. Estes são os ovos mais freqüentemente encontrados e eles têm dimensões muito parecidas. A maioria dos laboratórios não consegue distinguir os ovos de Cooperia, Haemonchus, Trichostrongylus, Ostertagia e Oesophagostomum, então dão o diagnóstico de presença de Strongylideos ou Trichostrongilídeos nas fezes. Os ovos de vermes redondos como Trichuris sp. (com plugues polares), Strongyloides sp. (com larva no interior) ou os muito grandes como Nematodirus sp. são facilmente reconhecidos. Uma infecção com trematódeos como a Fasciola hepatica é facilmente identificada pelos ovos típicos (amarelos e grandes com um opérculo). Se forem achados segmentos ou cadeias inteiras de segmentos maduros nas fezes um exame ao microscópio poderá confirmar uma infecção por Moniezia sp. com típicos ovos irregulares (Figura 5) (GEORGI, 1982). 
ALVES, D.P., SANTILIANO, F.C. e ALMEIDA, B.R. Epidemiologia das helmintoses gastrointestinais em bovinos. PUBVET, Londrina, V. 6, N. 25, Ed. 212, Art. 1414, 2012.
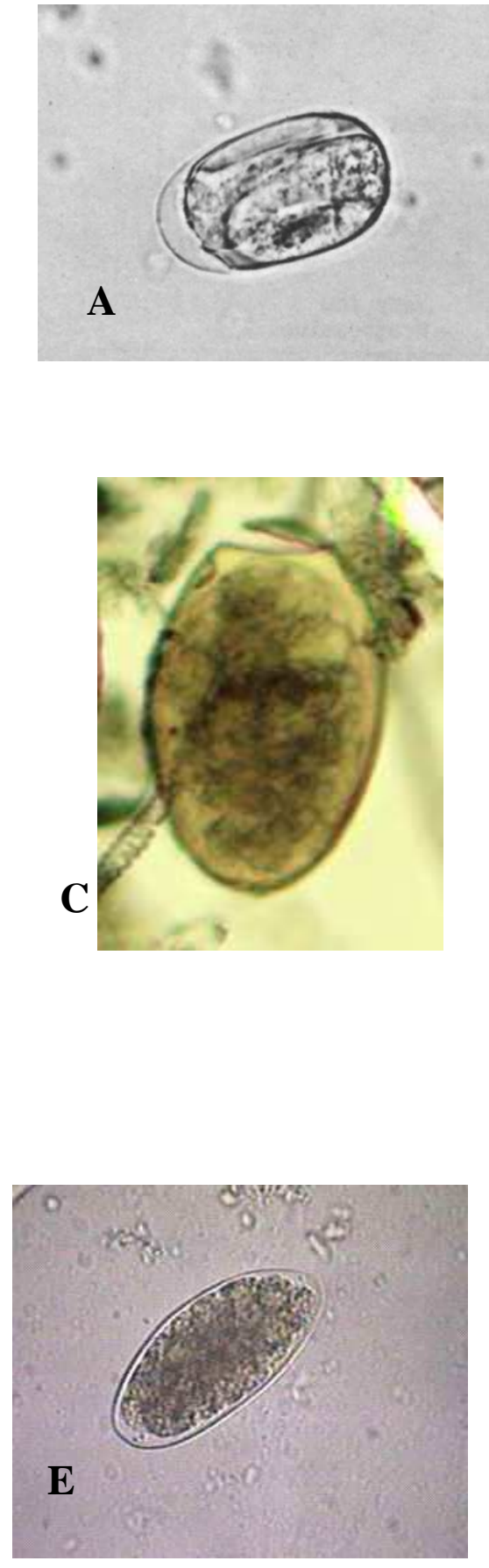
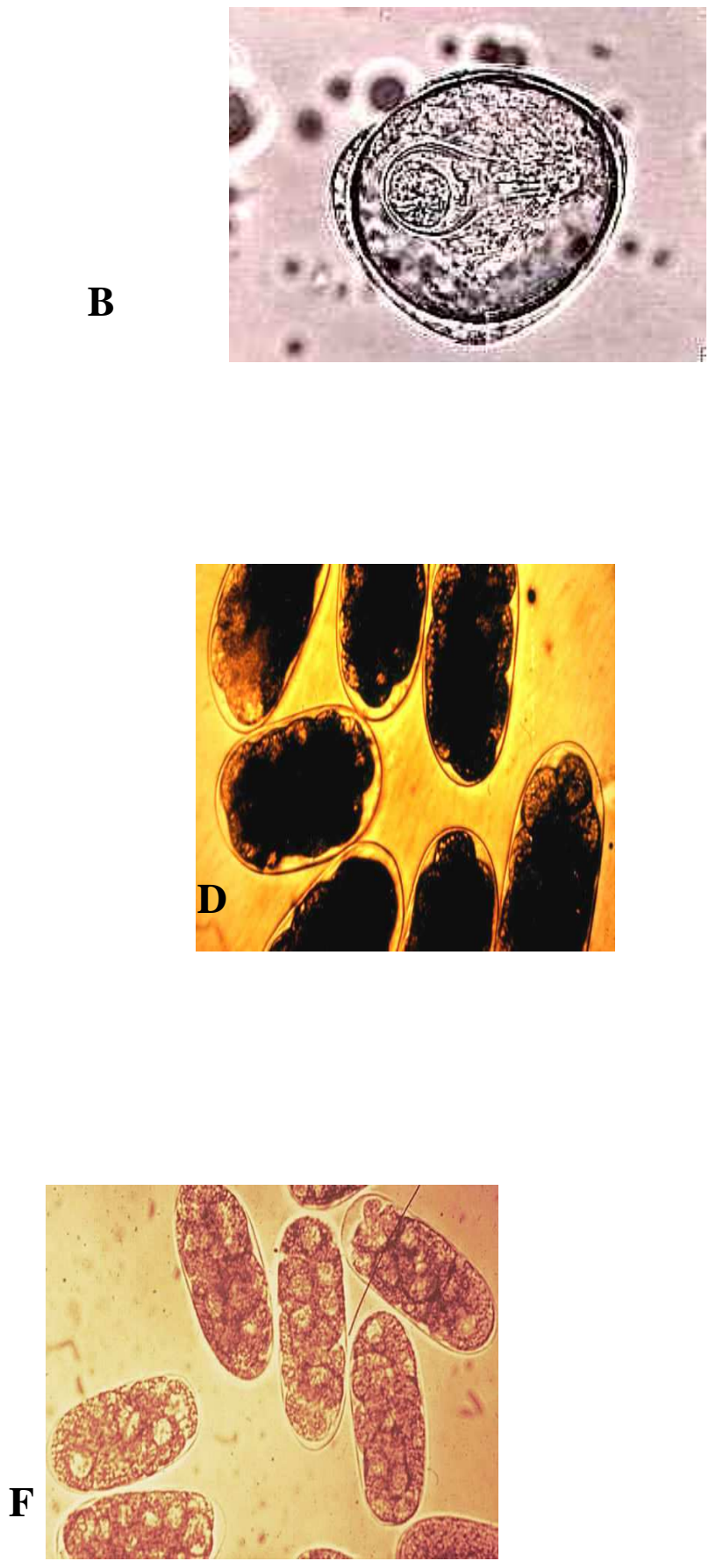
ALVES, D.P., SANTILIANO, F.C. e ALMEIDA, B.R. Epidemiologia das helmintoses gastrointestinais em bovinos. PUBVET, Londrina, V. 6, N. 25, Ed. 212, Art. 1414, 2012.
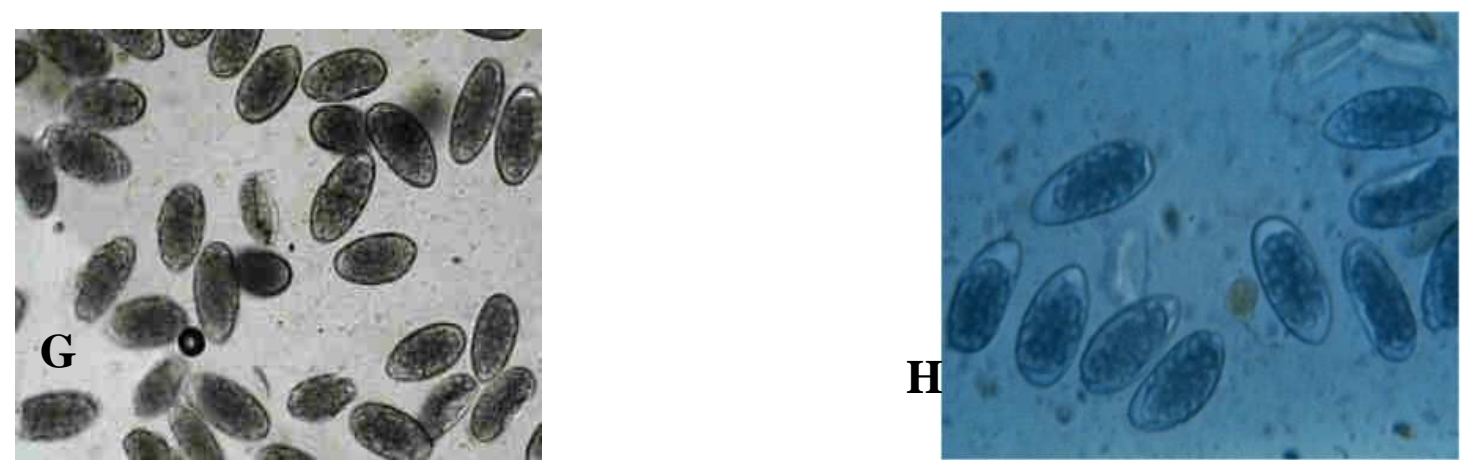

FIGURA 5: Representação esquemática dos ovos de alguns gêneros de parasitos encontrados em bovinos. A - Strongyloides papillosus; B - Moniezia; C Fasciola hepatica; D- Bunostomum; E - Trichostrongylus; F - Cooperia; G Haemonchus; H - Oesophagostomum. Fonte: Universidade Federal de Santa Maria. Disponível em: <http://w3.ufsm.br/parasitologia/arquivospagina/ovos debovinos.htm\#Trichostrongylus>. Acesso em: 10 maio 2012.

\subsection{Sinais clínicos das helmintoses em bovinos}

A maior parte dos animais criados a campo, em criação extensiva, apresenta parasitismo por uma ou mais espécies de helmintos. Entretanto, o parasitismo, nem sempre pode ser considerado sinônimo de enfermidade, pois geralmente a maioria dos bovinos se encontram em boas condições físicas. Isto ocorre pelo fato dos hospedeiros terem mecanismos imunológicos que permitem manter a população de endoparasitos sobre controle (AMARANTE, 2005).

O equilíbrio físico e o mecanismo imunológico dos animais podem ser alterados por diversos fatores tais como o clima, o nível nutricional, a raça, idade e o estado fisiológico (COOP e KYRIAZAKIS, 1999). Muitas vezes, o rompimento do equilíbrio é produzido pela ação do próprio homem através de medidas 
ALVES, D.P., SANTILIANO, F.C. e ALMEIDA, B.R. Epidemiologia das helmintoses gastrointestinais em bovinos. PUBVET, Londrina, V. 6, N. 25, Ed. 212, Art. 1414, 2012.

indevidas de manejo e utilização incorreta de medicamentos antiparasitários (AMARANTE, 2001).

As consequências das helmintoses gastrintestinais estão relacionadas ao número e espécies de larvas a que o animal é exposto e a quantidade de parasitos que se estabelecem em seu trato gastrintestinal. Por outro lado, o grau de infecção por nematóides gastrintestinais adquiridos pelos animais é dependente de uma série de fatores que muitas vezes se inter-relacionam. Estes incluem os efeitos diretos e indiretos de condições climáticas que podem determinar a taxa de infestação da pastagem, comportamento de pastejo dos animais, infecções prévias e estado fisiológico dos animais (WALLER, 2005).

As infecções parasitárias do rebanho geralmente são mistas e os efeitos patológicos causados pelos nematóides gastrintestinais são variados e dependem, dentre outros fatores, do tipo de migração e da localização final dos vermes (ARAÚJO e MADRUGA, 2001).

Os bovinos são suscetíveis a uma variedade enorme de helmintos, incluindo Ostertagia, Haemonchus, Cooperia, Trichostrongylus e Oesophagostomum. De todas as espécies de nematódeos, a Ostertagia ostertagi é a capaz de causar maiores perdas econômicas (SMITH, 2006).

A destruição morfológica e funcional das glândulas gástricas do abomaso está relacionada a espécies do gênero Ostertagia causando redução na acidez do fluido abomasal. A sintomatologia clínica ocasionada por Haemonchus é a hemorragia que surge na mucosa, nos locais onde o helminto se fixa podendo ocasionar em quadros agudos gastrite hemorrágica. O hábito de hematofagia deste parasito pode levar a quadros de anemia. Algumas espécies dos gêneros Cooperia e Trichostrongylus, durante a penetração na superfície epitelial do intestino delgado, podem levar a erosões na mucosa resultando em perda de proteínas plasmáticas e atrofia das vilosidades, reduzindo a superfície de absorção de nutrientes e líquidos levando a quadros de diarréia. Parasitos do 
ALVES, D.P., SANTILIANO, F.C. e ALMEIDA, B.R. Epidemiologia das helmintoses gastrointestinais em bovinos. PUBVET, Londrina, V. 6, N. 25, Ed. 212, Art. 1414, 2012.

gênero Oesophagostomum migram profundamente na mucosa do intestino, provocando uma resposta inflamatória com formação de nódulos, podendo levar a quadros de colite ulcerativa em conseqüência ao quadro de diarréia esverdeada, perda de peso e inapetência, levando na fase final da doença ao desenvolvimento de anemia e hipoalbuminemia, devido à perda protéica e extravasamento de sangue através da mucosa lesada e edema submandibular (Figura 6) (URQUHART et al.,1996).

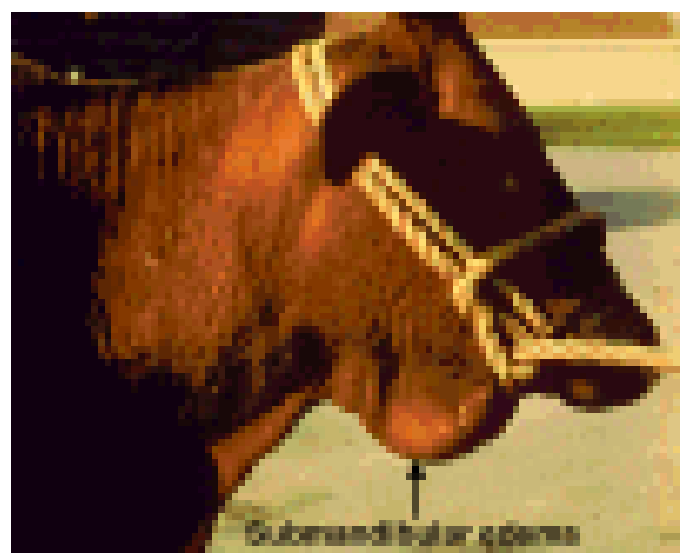

FIGURA 6: Bovino apresentando edema submandibular causado por infecção de Ostertagia ostertagi. Fonte: Universidad de Buenos Aires Disponível em: <http://ar.geocities.com/vetterworld/parasitologia/helm_p_haemonchus.htm>. Acesso em: 10 maio 2012.

Os trematódeos podem causar doença a fasciolose em forma aguda ou crônica em bovinos, ou em raros casos, subaguda. Os sinais podem consistir em perda de peso, emaciação, depressão, anorexia, pelagem áspera, anemia, hipoproteinemia, edema submandibular e icterícia discreta (SMITH, 2006).

A enfermidade aguda ocorre quando os animais ingerem grande quantidade de metacercárias em um curto intervalo de tempo. As larvas migram de forma maciça pelo intestino, peritônio e parênquima hepático provocando lesões 
ALVES, D.P., SANTILIANO, F.C. e ALMEIDA, B.R. Epidemiologia das helmintoses gastrointestinais em bovinos. PUBVET, Londrina, V. 6, N. 25, Ed. 212, Art. 1414, 2012.

intensas (SOULSBY, 1987). A forma crônica ocorre pela ingestão de poucas metacercárias, mas durante um longo período, levando a uma sintomatologia mais branda (GONZÁLEZ, 1982).

\section{EPIDEMIOLOGIA}

Diversos fatores influenciam a incidência e a prevalência das verminoses gastrintestinais, entre estes existem diversos fatores físicos, tais como: chuva, temperatura, umidade relativa, umidade e temperatura do solo, evapotranspiração e radiação solar (SAUERESSIG, 2006).

As variações sazonais na dinâmica das populações dos helmintos são reguladas, principalmente, pelas condições climáticas sobre os estádios de vida livre, pela raça e pela susceptibilidade individual do hospedeiro. A interação hospedeiro versus parasito é influenciada pela precipitação pluvial, faixas climáticas favoráveis, concentração de animais por área, faixa etária e índice nutricional (PIMENTEL e FONSECA, 2002).

Estes fatores têm levado ao desenvolvimento de pesquisas alternativas para o controle destes parasitos, como: manejo de pastagens (BRUNDSON, 1980), seleção de animais geneticamente resistentes (FRISCH e VERCOE, 1984), desenvolvimento de vacinas (EMERY, 1996) e controle biológico utilizando fungos nematófagos (GRONVOLD et al., 1993; ARAÚJO et al., 1996), sendo este último considerado um dos mais promissores (LARSEN, 1999).

Ao examinar a distribuição estacional dos helmintos gastrintestinais de bezerros em região de clima Aw do Estado do Rio de Janeiro, observou-se que durante o verão o número de helmintos foi pequeno, provavelmente devido às temperaturas elevadas sobre as larvas de pasto e ao bom estado nutricional dos animais nesta época do ano (Quadro 1) (PIMENTEL e FONSECA, 2002). 
ALVES, D.P., SANTILIANO, F.C. e ALMEIDA, B.R. Epidemiologia das helmintoses gastrointestinais em bovinos. PUBVET, Londrina, V. 6, N. 25, Ed. 212, Art. 1414, 2012.

Quadro 2. Capacidade de sobrevivência de helmintos com potencial para diminuição da produtividade em bezerros no tipo climático Aw, no Estado do Rio de Janeiro (Classificação de Köpen)

\begin{tabular}{lll}
\hline \multicolumn{1}{c}{ Tipo de clima Aw } & \multicolumn{1}{c}{ Sobrevivência no ambiente } \\
\cline { 2 - 3 } & \multicolumn{1}{c}{ Ótima ${ }^{1}$} & \multicolumn{1}{c}{ Mínima ou nenhuma ${ }^{2}$} \\
\hline & & Dictyocaulus vivipanus \\
Clima tropical, inverno & Haemonchus placei & Trichostrongylys axei \\
seco com menos de & Cooperia sp & Bunostomum plebotomum \\
$60 \mathrm{~mm}$ precipitação e & Oesophagostomum radiatum & Moniesia benedeni \\
verão chuvoso & & Trichuris sp
\end{tabular}

${ }^{1}$ Helminto recuperado pelo período de dois ou mais meses seguidos.

${ }^{2}$ Helminto recuperado esporadicamente.

QUADRO 1: Capacidade de sobrevivência de helmintos com potencial para diminuição da produtividade em bezerros no tipo climático Aw, no Estado do Rio de Janeiro (Classifcação de Kopen). Adaptado de PIMENTEL e FONSECA, 2002.

A faixa etária do hospedeiro e a intensidade do parasitismo também são dados epidemiológicos importantes para influenciar a incidência e prevalência dos parasitos e são fatores essenciais para estabelecer-se um programa de controle das verminoses intestinais (BRESCIANI et al., 2001).

Araújo e Lima (2005) observaram no município de Carandaí, estado de Minas Gerais, que o maior número de parasitos recuperados ocorria durante o período chuvoso e nos meses subseqüentes a este, destacando que os níveis de infecção são mais altos durante o período chuvoso e estão relacionados à maior umidade, a qual favorece o desenvolvimento de estádios de vida livre dos parasitos e a migração das larvas infectantes do bolo fecal para as pastagens adjacentes.

Segundo estudos de Cubillán et al (2007), houve um efeito significativo entre os meses do ano sobre a prevalência de helmintoses em rebanho bovino e a OPG (contagem de ovos por grama de fezes), observando uma associação entre estes parâmetros e a precipitação anual. 
ALVES, D.P., SANTILIANO, F.C. e ALMEIDA, B.R. Epidemiologia das helmintoses gastrointestinais em bovinos. PUBVET, Londrina, V. 6, N. 25, Ed. 212, Art. 1414, 2012.

Repossi Junior et al. (2006) estudaram no município de Alegre, estado do Espírito Santo, a prevalência de parasitoses gastrintestinais em bezerros em 12 propriedades e observaram que Trichuris sp. foi diagnosticado em $50 \%$ das propriedades, Moniezia sp. em 25\%, Strongyloides papillosus em 33,3\% e em todas $(100 \%)$ constatou-se a presença de animais positivos para oocistos de coccídeos e ovos do tipo Strongyloidea (Figura 7), o que demonstra que a ocorrência de determinados parasitos se relacionam à faixa etária dos hospedeiros.

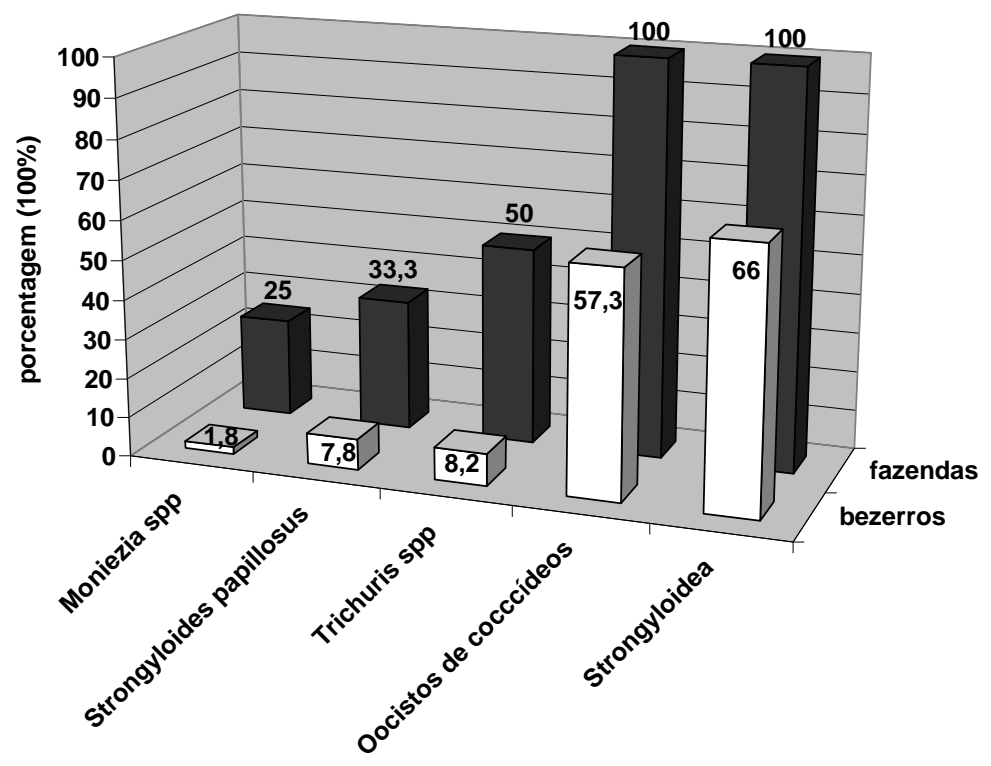

FIGURA 7: Prevalência dos principais parasitos gastrintestinais nos bezerros e nas propriedades leiteiras do município de Alegre, ES (REPOSSI JUNIOR et al, 2006).

Bresciani et al (2001) avaliaram a freqüência e intensidade parasitária de helmintos gastrintestinais em bovinos, com idade entre 24 e 30 meses, abatidos em frigorífico no estado de São Paulo, e observaram que infecções mistas normalmente ocorrem em $52,1 \%$ dos animais, puras em $12,0 \%$ e $22,9 \%$ deles não apresentavam infecções helmínticas. As espécies de helmintos identificadas foram: Cooperia punctata, Cooperia pectinata, Haemonchus similis, Haemonchus 
ALVES, D.P., SANTILIANO, F.C. e ALMEIDA, B.R. Epidemiologia das helmintoses gastrointestinais em bovinos. PUBVET, Londrina, V. 6, N. 25, Ed. 212, Art. 1414, 2012.

placei e Oesophagostomum radiatum. A proporção de nematóides na primavera foi superior ao outono e ao verão, indicando correlação positiva entre os parasitos e a estação anual, visto que estes se desenvolvem normalmente em locais onde o índice pluviométrico encontra-se alto.

Estudos realizados em diversas regiões têm demonstrado uma maior prevalência dos gêneros Cooperia, Haemonchus, Oesophagostomum, Trichostrongylus, Trichuris e Bunostomum em bovinos (FURLONG et al., 1985; GIRÃo et al., 1985; BIANCHIN et al., 1990; LIMA et al., 1990; ARAÚJo et al., 1992a; HONER e VIEIRA BRESSAN, 1992).

Em estudos conduzidos na região Centro-Oeste do Brasil foi observado que existe uma relação inversa entre as cargas de parasito nos animais e a infestação das pastagens durante a estação seca. O número de larvas de terceiro estádio ( $L$ 3) nas pastagens foi maior no período chuvoso que no período seco. No período seco do ano, as fezes podem funcionar como reservatório de $L 3$, porém não existe umidade suficiente para que elas se espalhem nas pastagens. Contudo, em clima tropical úmido, a umidade e o calor favorecem o rápido desenvolvimento de ovos e larvas, mas por sua vez aumentam a taxa de mortalidade de larvas infectantes nas pastagens (BANKS et al., 1990; BARGES et al., 1994).

\subsection{Hipobiose ou desenvolvimento larval inibido}

Pode-se definir este fenômeno como a interrupção temporária no desenvolvimeto de um nematóide num exato momento do seu desenvolvimento parasitário. A hipobiose tem grande importância epidemiológica para os nematóides gastrintestinais, pois assegura a sobrevivência dos mesmos em períodos de adversidade e a subseqüente maturação das larvas inibidas aumenta a contaminação do meio ambiente resultando em doença clínica nas espécies hospedeiras (URQUHART et al.,1996). 
ALVES, D.P., SANTILIANO, F.C. e ALMEIDA, B.R. Epidemiologia das helmintoses gastrointestinais em bovinos. PUBVET, Londrina, V. 6, N. 25, Ed. 212, Art. 1414, 2012.

O ambiente tem influência direta no processo de inibição que ocorre no trato gastrintestinal, em que as larvas hipobióticas permanecem na submucosa do estômago e intestino dos animais em processo de ibernação (Figura 7). Nos períodos secos, frios e quentes, os quais são desfavoráveis, o número de larvas inibidas permanece maior. Entretanto, quando as condições de umidade e temperatura ambiente são favoráveis, as larvas retornam à luz do estômago e ou intestino e completam a maturação sexual, determinando aumento de larvas infectantes nas pastagens e ocasionando surtos (SAUERESSIG, 2006).

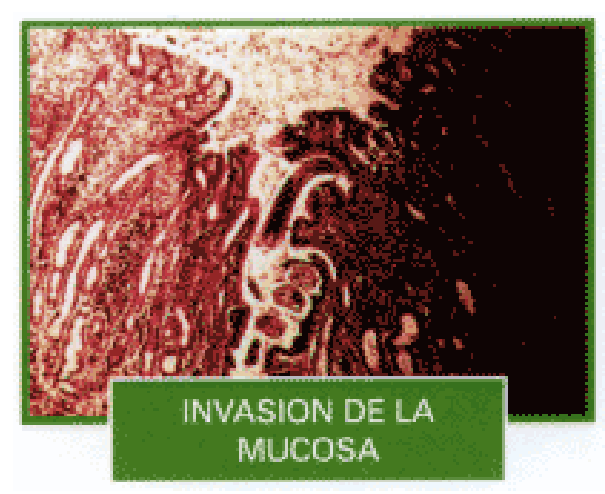

FIGURA 8: Mucosa abomasal demonstrando aspecto dilatado dos espaços intercelulares das glândulas pela presença de larvas em hipobiose. Fonte: Faculdades UNICEN. Disponível em: <http://www.produccionbovina.com/sanidad_intoxicaciones_metabolicos/parasita rias/parasitarias_bovinos/65-manual_tecnico.htm>. Acesso em: 10 maio 2012.

O desenvolvimento larval inibido pode ocorrer como resultado de imunidade adquirida ou imunidade relacionada à faixa etária do hospedeiro. A maturação dessas larvas pode estar ligada ao ciclo reprodutivo do hospedeiro, ocorrendo normalmente nas proximidades do parto em fêmeas (URQUHART et al.,1996) . 
ALVES, D.P., SANTILIANO, F.C. e ALMEIDA, B.R. Epidemiologia das helmintoses gastrointestinais em bovinos. PUBVET, Londrina, V. 6, N. 25, Ed. 212, Art. 1414, 2012.

\subsection{Aumento de ovos nas fezes na fase peripuerperal}

Este fenômeno ocorre no período anterior ao parto e no período pós-parto havendo aumento na eliminação de ovos nas fezes. A queda de imunidade temporária na fase imediatamente anterior ao parto e na fase subseqüente ao mesmo pode ser a causa deste aumento na eliminação de ovos nas fezes por fêmeas adultas. Alguns trabalhos relacionam o aumento da prolactina neste período com o aumento do parasitismo e a queda de imunidade dos animais, determinando o aumento da produção de prolactina como responsável pela queda de imunidade. Portanto, animais de alta produção leiteira em seu pico de lactação estão mais suscetíveis aos efeitos patogênicos ocasionados pelos parasitos do que uma fêmea que não esteja na fase de pico, levando a uma queda na produção leiteira normalmente não percebida pelo criador (SAUERESSIG, 2006).

\section{CONSIDERAÇÕES FINAIS}

No Brasil a pecuária bovina baseia-se basicamente em sistema extensivo para gado de corte e sistema intensivo para a bovinocultura leiteira. Porém tanto a pecuária de corte como a de leite podem ser baseadas em ambos os sistemas de criação. Alguns fatores contribuem para a redução da produtividade do rebanho em todos os sistemas de criação, entre estes as flutuações estacionais das pastagens, as carências nutricionais, o manejo inadequado, a alta incidência de parasitos, dentre outras enfermidades. No sistema de criação intensivo estes fatores acarretam maiores prejuízos aos animais.

Os parasitos influenciam de maneira significativa na mortalidade e na eficiência produtiva de um rebanho bovino. Nas áreas tropicais esta influência normalmente é atribuída por helmintoses gastrintestinais sendo os animais infectados portadores, de maneira geral, por várias espécies de helmintos 
ALVES, D.P., SANTILIANO, F.C. e ALMEIDA, B.R. Epidemiologia das helmintoses gastrointestinais em bovinos. PUBVET, Londrina, V. 6, N. 25, Ed. 212, Art. 1414, 2012.

simultaneamente. Como nestas áreas o índice de mortalidade relacionado às infecções é baixo, a parasitose não é observada como um problema grave pelos produtores rurais. Todavia, estes devem preocupar-se, pois as verminoses podem causar baixos índices de desenvolvimento dos bovinos jovens, por ser a faixa etária mais acometida normalmente.

Como disposto anteriormente, os efeitos negativos do parasitismo dependem de fatores como: espécie, número e patogenicidade do parasito; localização no hospedeiro; condição de saúde, idade e susceptibilidade genética do hospedeiro. A incidência e prevalência das helmintoses gastrintestinais são influenciadas por fatores ambientais que favorecem o ciclo evolutivo dos parasitos, acarretando maior período em que os animais permanecem infectados no rebanho, sendo o clima tropical extremamente favorável.

Estudos estão sendo realizados com o objetivo de tentar minimizar os prejuízos econômicos relacionados a estas parasitoses através do desenvolvimento de métodos alternativos de controle. Novas moléculas estão sendo pesquisadas para a utilização como anti-helmínticos com objetivo de causar pouca ou nenhuma resistência parasitária e poucos efeitos residuais nas carcaças dos animais.

Além disso, métodos de compostagem das fezes estão sendo avaliados a fim de diminuir o desenvolvimento das larvas dos parasitos e consequentemente diminuir as chances de continuidade do ciclo de vida dos mesmos.

Assim, espera-se que os estudos epidemiológicos das helmintoses gastrintestinais de bovinos em diferentes regiões do Brasil atrelado a estudos de novas alternativas de controle, possam contribuir de forma eficiente com a redução das perdas econômicas geradas por estas enfermidades na pecuária bovina, com o objetivo de favorecer ao produtor rural com o aumento da lucratividade e com o consumidor final dos subprodutos destes animais. 


\section{REFERÊNCIAS}

AMARANTE, A. F. T. Controle integrado de helmintos de bovinos e ovinos. Revista Brasileira de Parasitologia Veterinária, v.13, s.1, p.68-71, 2004.

AMARANTE, A. F. T. Controle da verminose ovina. Revista do Conselho Federal de Medicina Veterinária, n.34, p.19-30, 2005.

AMARANTE, A.F.T. Controle de endoparasitoses dos ovinos. In: A produção animal na visão dos brasileiros. Piracicaba: FEALQ. p.461-473, 2001.

ANUALPEC 2003: Anuário estatístico da produção animal. São Paulo: FNP Consultoria \& Comércio. 2003. 380 p. Disponível em < http:// w3. ufsm.br/parasitologia/arquivospagina/ovosdebovinos.htm htm\#Trichostrongylus > Acesso em 09 de Maio de 2008.

ARAÚJO, J.V.; GUIMARÃES, M. P.; LIMA, P.A.S.; LIMA, W.S. Avaliação de tratamentos antihelmínticos em bezerros da bacia leiteira de Muriaé. Pesquisa Agropecuária Brasileira, v.27, n.1, p.7-14, 1992a.

ARAÚJO, J.V.; NETO, A.P.; AZEVEDO, M.H.F. Screening parasitic nematodetrapping fungi Arthrobotrys for passage through the gastrointestinal tract of calves. Arquivo Brasileiro de Medicina Veterinária e Zootecnia, v 48, p. 543-552, 1996.

ARAÚJO, F.R.; MADRUGA, C.R. Imunidade contra helmintos In: MADRUGA, C.R.; ARAÚJO, F.R.; SOARES, C.O (Eds). Imunodiagnóstico em Medicina Veterinária. Campo Grande: Embrapa Gado de Corte. p.97-110, 2001.

ARAÚJO, R, N; LIMA, W.S. Infecções helmínticas em um rebanho leiteiro na região de Campo das Vertentes de Minas Gerais. Arquivo Brasileiro de Medicina Veterinária e Zootecnia. Universidade Federal de Minas Gerais, v.57, supl.2, p.186-193, 2005.

BANKS. D.J.D. et al. Development an survival of infective larvae of Haemonchus contortus and Trichostrongylus colubriformis in a tropical environment. International Journal of Parasitology. Oxford, v.20, p.155-160, 1990.

BARGER, I.A. et al. Rotacional grazing for control of gastrointestinal nematodes of goats in a wet tropical environment. Veterinary Parasitology. Amsterdam, v.53, p.109-116, 1194.

BIANCHIN, I.; HONER, M.R.; NASCIMENTO, Y.A. The epidemiology of helminths in Nellore beef cattle in the cerrados of Brazil. In: Epidemiology of bovine nematode parasites in the americas. Guerreiro, J.; ILEANING. W.H. D. (Eds) p.41-49, 1990.

BRESCIANI, K.D, et al. Frequência e intensidade parasitárias de helmintos gastrintestinais em bovinos abatidos em frigorífico da região noroeste do estado de São Paulo, SP, Brasil. Ciências Agrárias, Londrina, v.22, n.1, p. 93-7, 2001.

BRUNDSON, R.V. Principles of helminth control.Veterinary Parasitology, v. 6, p.185-215, 1980. 
COOP, R.L.; KYRIAZAKIS, I. Nutrition-parasite interaction.Veterinary Parasitology,v.84, p.187204, 1999.

CORRÊA, O. Doenças parasitárias dos animais domésticos. 4. Ed, Porto Alegre. Sulina, cap. 2. p. $121,1983$.

CUBILLÁN, F.A. et al. Prevalencia e dinâmica de HPG mensual de Fasciola hepatica y otros helmintos en un rebaño bovino de una zona inundable tropical. Revista Científica, FCV-LUZ, $v$. XVII, n.2, p. 111-116, 2007.

EMERY, D.L. Vaccination against worm parasites of animals. Internacional Journal for Parasitology, v.64, p.31-45, 1996.

FRISCH, J.E.; VERCOE, J.E. An analysis of different cattle genotypes reared in different environments. Journal of Agricultural Science., v.103, p.137-153, 1984.

FURLONG, J.; ABREU, H.G.L. VERNEQUE, R.S. Parasitoses dos bovinos da zona da mata de Minas Gerais. I. Comportamento estacional de nematódeos gastrintestinais. Pesquisa Agropecuária Brasileira. v.20, n.1, p.143-153, 1985.

GEORGI, J.R. Parasitologia veterinária. 3. ed. Rio de Janeiro, Brasil. Interamericana, 1982.

GIRÃO, E.S.; GIRÃO, R.N.; MEDEIROS, L.P. Prevalência, intensidade de infecção e variação estacional de helmintos em bovinos no estado do Piauí. Pesquisa Agropecuária Brasileira, v.20, n.8, p.889-897, 1985.

GRONVOLD, J.; WOLSTRUP, J.; NANSEM, P.; HENRIKSEN, S. A.; LARSEN, M.; BRESCIANI, J. Biological control of nematode parasites in cattle with nematode trapping fungi: a survey of Danish studies. Veterinary Parasitology. v.48, p.311- 325, 1993.

GONZÁLES, H. Perdidas econômicas producidas por las parasitosis de los rumiantes. In: JORNADAS MÉDICO VETERINÁRIAS, 8.:1982, Valdivia. Anais ... Valdivia : Universidad Austral de Chile, p. 39-48, 1982.

HONER, M.R.; BIANCHIN, I. Considerações básicas para um programa de controle estratégico da verminose bovina em gado de corte no Brasil. Campo Grande: Embrapa-CNPGC,. 53p. (Embrapa-CNPGC. Circular Técnica 20). 1987.

HONER, M. R VIEIRA -BRESSAN, M.C.R. Nematódeos de bovinos no Brasil - o estado da pesquisa. Revista de Parasitologia Veterinária ,v.1, p.67-69, 1992.

LARSEN, M. Biological Control of Helminths. Internacional Journal for Parasitology, v.29, p.139-146,1999.

LIMA, W.S. Dinâmica das populações de parasitos gastrintestinais em bovinos de corte, alguns aspectos da relação parasito-hospedeiro e do comportamento dos estádios de vida livre na região do vale do Rio Doce, MG. Brasil. Belo Horizonte: Instituto de Ciências Biológicas da UFMG,178 p. , 1989. (Tese, doutorado). 
LIMA, J.D.; LIMA, W.S.; GUIMARÃES, A.M.; LOSS, A.C.S.; MALACCO, M.A. Epidemiology of bovine nematodes parasites in southeastern Brazil. In: Epidemiology of bovine nematode parasites in the Americas. Guerreiro, J.; ILEANING. W.H. D. (Eds), p.41-49, 1990.

NISHI, Sandra Mayumi; RICHTZENHAIN, Leonardo José; GENNARI, Solange Maria. Serum IgG level in calves experimentally infected with Haemonchus placei. Brazilian Journal of Veterinary Research and Animal Science, São Paulo, v. 39, n. 2, 2002.

PADILHA, T. Controle da verminose gastrintestinal em pequenos ruminantes nas regiões áridas e semi-áridas do nordeste do Brasil In: Controle dos nematódeos gastrintestinais dos ruminantes. Terezinha Padilha (Ed.). Coronel Pacheco: EMBRAPA-CNPGL, p.169-178, 1996.

PIMENTEL NETO, Manoel; FONSECA, Adivaldo Henrique da. Epidemiology of pulmonary and gastrintestinal helmintoses in calves in the lowland of the state of Rio de Janeiro.Pesquisa Veterinária Brasileira, Rio de Janeiro, v. 22, n. 4, 2002.

QUEIROZ, V. S, et al. Fasciola hepatica (Trematoda, Fasciolidae): Estudo epidemiológico nos municípios de Bocaiúva do Sul e "Tunas do Paraná" (Brasil). Acta Biológica Paranaense, Curitiba, v. 31, p. $99-111,2002$.

REPOSSI JUNIOR, P. F., et al. Prevalência e controle das parasitotes gastrintestinais em bezerros de propriedades leiteiras no município de Alegre, Espírito Santo. Revista Brasileira de Parasitologia Veterinária. Universidade Federal Rural do Rio de Janeiro, v.15, n.4, p. 147-150, 2006.

SAUERESSIG, T.M., Produção de proteína animal de qualidade com sustentabilidade: controle racional das parasitoses dos bovinos. Embrapa Cerrados. Planaltina, DF. ISSN, 1517 - 5111; $157,2006$.

SERRA-FREIRE, N. M. Fasciolose hepática no Brasil: Análise retrospectiva e prospectiva. In: Caderno Técnico-científico da Escola de Medicina Veterinária, Universidade do Rio Grande, ano 1, n.1,p. 9-70, ed. Unigranrio,1999.

SMITH, B. P. Medicina interna de grandes animais. 3. ed. São Paulo, Brasil. Manole, 2006.

SOULSBY, E. J. L. Parasitologia y enfermedades parasitarias. 7 ed. México : Interamericana, 823 p, 1987.

TONGSON, M.S., BALEDIATA, E. Epidemiology of bovine parasitic gastroenteritis. Journal of Veterinary Medicine, Berlin, v.11, p.63-72, 1972.

URQUHART, G.M. et al., Helmintologia veterinária. In:

Rio de Janeiro: Guanabara Koogan, cap. 1, p. 89 - 98, 1996.

Parasitologia Veterinária. 2. ed.

WALLER, P.J., LARSEN, M. The role of nematophagous fungi in the biological control of nematode parasites of livestock. Internacional Journal for Parasitology, v.23, p.539-546,1993.

WALLER, P.J. Sustainable helminth control of ruminants in developing countries. Veterinary Parasitology, v.71 p.195-207, 1997.

WALLER, P.J Sustainable nematode parasite control strategies for ruminant livestock by grazing management and biological control. Animal Feed Science and Techinology. 2005. 